\title{
Mudança estrutural da esfera privada? Big data e os desafios à antropologia política da modernidade
}

\author{
Structural change of the private sphere? Big data and \\ the challenges to the political anthropology of modernity
}

LEONARDO DA HORA (iDa

\section{Resumo}

Uma reflexão crítica sobre os caminhos e descaminhos das tecnologias contemporâneas se impõe com cada vez mais força na atualidade. Não se pode mais falar das dimensões "social" e "política" apenas se referindo à interação intersubjetiva; é preciso focar igualmente na interação humana com os aparatos técnicos. Tendo como pano de fundo a crescente digitalização da vida, acompanhada de processos de captação e armazenamento massivos de dados por parte de diferentes mecanismos e instâncias, gostaria de abordar, neste artigo, uma série de análises sobre os impactos do big data nos campos da economia, da política e da subjetividade a fim de colocar a seguinte questão: em que medida esse novo fenômeno não altera a configuração dos espaços de socialização e subjetivação, notadamente a esfera privada, de sorte a gerar um impacto na própria estruturação das democracias modernas? Tal questão se impõe na medida em que a antropologia política da modernidade é baseada, predominantemente, em uma noção substancial de sujeito autônomo, que possui na esfera privada um espaço fundamental de atividade e vivência cujo acesso lhe é privilegiado. Sendo assim, o objetivo do artigo é o de iniciar uma discussão sobre até que ponto as bases da antropologia política da modernidade não estariam sendo solapadas a partir de uma "mudança estrutural da esfera privada", uma vez que o acesso privilegiado do indivíduo a determinados dados privados poderia ser suplantado pelo

a Universidade Federal da Bahia (UFBA), Salvador, BA, Brasil. Doutor em Filosofia, e-mail: leonardojorgehp@gmail.com 
advento do Big Data, ameaçando um dos principais pressupostos teóricos e institucionais do liberalismo e da democracia moderna, a saber: a de que somos seres autônomos, responsáveis e os únicos capazes de legitimamente deliberar e tomar determinadas decisões. Procurarei trabalhar tal questionamento a partir de uma proposta de reatualização do conceito habermasiano de consciência tecnocrática.

Palavras-chave: Big data. Esfera privada. Autonomia. Filosofia política. Modernidade.

\section{Abstract}

A critical reflection on the paths and deviations of contemporary technologies imposes itself more and more strongly today. It is no longer possible to speak of the "social" and "political" dimensions simply referring to intersubjective interaction; it is also necessary to focus on human interaction with technical devices. Against the background of growing digitalization of life, accompanied by massive data capture and storage processes by different mechanisms and instances, I would like to address, in this article, a series of analyzes on the impacts of big data in the fields of economy, politics and subjectivity in order to ask the following question: to what extent does this new phenomenon change the configuration of spaces for socialization and subjectivation, notably the private sphere, generating an impact on the very structuring of modern democracies? Such a question is crucial since the political anthropology of modernity is based, predominantly, on a substantial notion of autonomous subject, who has in the private sphere a fundamental space of activity and experience whose access is privileged. Thus, the goal of the paper is to initiate a discussion about the extent to which the foundations of the political anthropology of modernity are not being undermined by a "structural transformation of the private sphere", since the individual's privileged access to certain private data could be supplanted by the advent of Big Data, threatening one of the main theoretical and institutional assumptions of liberalism and modern democracy, namely: that we are autonomous, responsible beings and the only ones capable of legitimately deliberating and making certain decisions. I will try to work on this question based on a proposal to update the Habermasian concept of technocratic consciousness.

Keywords: Big data. Private sphere. Political philosophy. Autonomy. Modernity. 


\section{Introdução}

Um dos fatos que marcam de modo mais específico a nossa época e que talvez a diferenciem de todas as outras é o de que produzimos - para parafrasear Marx “uma imensa coleção de dados". Senão vejamos: segundo pesquisadores da Escola de Informação de Berkeley, a humanidade acumulou pouco mais de 12 exabytes (1 exabyte $=$ mais de 1 bilhão de gigabytes) até o momento em que os computadores passaram a ser comercializados. Desde então, até 2006, acumulamos mais de 180 exabytes. De acordo com um estudo mais recente, o total atingiu mais de 1600 exabytes entre 2006 e 2011, passando assim da barreira do zettabyte (mil exabytes). A expectativa é que essa quantidade quadriplique a cada três anos, de modo que em 2015 já teríamos atingindo a casa dos 8 zettabytes (FLORIDI, 2014, p. 13). Por meio das novas tecnologias digitais de comunicação e informação, produzimos todos os dias dados suficientes para preencher oito vezes todas as bibliotecas dos EUA. Entramos assim na era do big data.

Bom, esse é certamente um fato que chama nossa atenção, mas ainda assim podemos nos perguntar: o que isso significa? Este fenômeno provoca alguma consequência notável para o modo como nos organizamos socialmente? No que se segue, gostaria de abordar uma série de análises sobre os impactos do big data no campo da economia, da política e da subjetividade a fim de colocar a seguinte questão: até que ponto esse novo fenômeno não altera a configuração dos espaços de socialização e subjetivação, notadamente a esfera privada, de sorte a gerar um impacto na própria estruturação das democracias modernas?

Coloco esta questão na medida em que a antropologia política da modernidade é baseada, predominantemente, em uma noção substancial de sujeito autônomo, que possui na esfera privada um espaço fundamental de atividade e vivência cujo acesso lhe é privilegiado. Tendo em vista este pano de fundo de crescente digitalização da vida, acompanhada de processos de captação e armazenamento massivos de dados por parte de diferentes mecanismos e instâncias, gostaria de discutir até que ponto a esfera privada, que serve de base à antropologia política da modernidade, não estaria sendo erodida, uma vez que o acesso privilegiado do indivíduo a determinados dados 
privados poderia ser suplantado, a ponto de ameaçar um dos principais pressupostos teóricos e institucionais do liberalismo e da democracia moderna.

\section{Humanismo e a antropologia política da modernidade}

Ao iniciar o seu Do contrato social, Rousseau se preocupa em afastar imediatamente todas as doutrinas políticas que depositam em outro lugar que não na vontade livre dos indivíduos a legitimidade da soberania política. Notadamente, ele recusa todas as doutrinas que fundam o poder na vontade de Deus: "Reconheço que todo o poder vem de Deus, mas também todas as doenças. Por isso será proibido chamar o médico?” (ROUSSEAU, 1987, p. 26). Passa-se então claramente de uma perspectiva, típica do período anterior, em que a legitimidade da soberania era pensada como derivada de Deus para um cenário antropocêntrico, em que o poder precisa derivar da própria vontade humana - e a doutrina de Rousseau é um belo exemplo desta tendência de fundo mais ampla no pensamento político moderno.

Mas não é só isso: temos igualmente o aparecimento de dois pressupostos extremamente importantes na antropologia política da modernidade: todos os humanos são (i) livres e (ii) iguais do ponto de vista da natureza, a desigualdade resultando de determinadas convenções sociais. No caso de Rousseau, como a vontade geral é a vontade do corpo político, e este se constitui de todos os associados reunidos em um povo, o soberano nada é senão um ser coletivo constituído por todos. Disso resulta que ninguém está fora da dupla relação súdito/cidadão, portanto, que ninguém está desobrigado das decisões do soberano enquanto súdito. Além disso, tanto a obediência à lei como a participação em sua autoria é feita em total igualdade, de modo que, para a deliberação política, todos têm as mesmas condições de participação e, para a obediência civil, a mesma igualdade de direitos e deveres.

Ora, se a legitimidade do poder tem de vir da vontade humana, temos uma valorização bastante significativa da própria experiência humana (e de todos os indivíduos em igual medida), o que implica valorizar em alguma medida todos os seus

atributos: suas atividades, seus sentimentos e, não por último, a razão humana. É interessante notar como Rousseau, mesmo não estando relacionado à tradição liberal 
e ao individualismo que geralmente caracteriza esta última, não deixa de afirmar que "Se, quando o povo suficientemente informado delibera, os Cidadãos não tivessem nenhuma comunicação entre eles, do grande número de pequenas diferenças resultaria sempre a vontade geral, e a deliberação seria sempre boa" (ROUSSEAU, 1987, p. 47). Ou seja, da experiência individual de cada cidadão pode se formar uma opinião que, de alguma forma, convergiria com todas as demais na direção da formação da vontade geral.

Trata-se evidentemente de uma concepção polêmica, que mereceu contemporaneamente a censura de alguém como Jürgen Habermas, que atribui a Rousseau (assim como a Kant, entre outros) as limitações típicas de uma filosofia da consciência, centrada no sujeito e não na intersubjetividade (Cf. HABERMAS, 1994). Contudo, subjetivo ou intersubjetivo, Habermas se junta a Rousseau e também a Kant na defesa da base normativa da modernidade política, pautada pelas concepções de liberdade e igualdade entre os cidadãos. É por isso que Habermas defende o mundo da vida, espaço em que se dão os fluxos comunicativos e a formação democrática da vontade política, contra os avanços sistêmicos e tecnocráticos que visam se autonomizar em relação às experiências práticas dos indivíduos. Isto é, mais uma vez reconhecemos aqui esse leitmotiv "humanista" que visa centrar a legitimidade do poder nas próprias capacidades humanas de deliberação e tomada de decisões. Somos todos nós, de modo livre, autônomo, igualitário e desta vez intersubjetivamente, que temos de conduzir o processo de formação da opinião e da vontade.

\section{Autonomia e esfera privada}

Temos talvez em John Locke a concepção mais representativa da doutrina do liberalismo clássico, segundo a qual a principal finalidade do pacto e da sociedade civil é a proteção da liberdade individual e da propriedade privada. A autonomia dos sujeitos, neste caso, não pode ser compreendida sem a noção de esfera privada. No entanto, podemos também compreender a importância e centralidade da esfera privada em chave "republicana". O próprio Habermas concebe uma cooriginariedade entre autonomia privada e autonomia pública, ou, para utilizar os termos de Benjamin 
Constant e Isaiah Berlin, uma mútua fundamentação dos âmbitos da liberdade positiva dos antigos, e da liberdade negativa dos modernos. Ou seja, como nos mostra Repa (2013), Habermas sustenta que de um lado os direitos subjetivos só recebem uma positivação jurídica concreta por meio da autonomia pública. Por outro lado, a autonomia privada ela mesma é uma condição indispensável para a participação autônoma na discussão pública sobre as leis. Pode-se dizer que não haveria liberdade comunicativa se não houvesse também a liberdade negativa de não participar da comunicação pública, o que por sua vez é garantido pelas leis que sustentam a autonomia privada. Estas sustentam a independência e a privacidade necessárias para uma participação livre e qualificada na esfera pública.

Do mesmo modo, Cohen (2000) chama a atenção para o fato de que indivíduos autônomos não caem do céu; eles precisam desenvolver a capacidade de decidir e tomar posição por eles mesmos. A autonomia requer um espaço de relativa independência em relação ao escrutínio e à influência externa. Ou seja, segundo Cohen, a autonomia exige um campo de experimentação dentro do qual é possível a construção da consciência do self. Nesse sentido, a esfera privada aparece como uma dimensão essencial para a formação de indivíduos autônomos, mesmo do ponto de vista da autonomia pública. Trata-se de um espaço de liberdade de experimentação e construção da identidade. A experiência de estar sendo observado tende a restringir ex ante o espectro identitário e comportamental. Ora, um debate público robusto e diverso pressupõe a oportunidade de as pessoas experimentarem e desenvolverem diferentes perspectivas em privado.

Hannah Arendt também não deixou de reconhecer esse aspecto crucial da esfera privada, incluindo a propriedade privada (em um sentido não possessivo):

Assim, não é realmente exato dizer que a propriedade privada, antes da era moderna, era vista como condição axiomática para admissão à esfera pública; ela era muito mais que isso. A privatividade era como que o outro lado escuro e oculto da esfera pública; ser político significava atingir a mais alta possibilidade da existência humana; mas não possuir um lugar próprio e privado (como no caso do escravo) significava deixar de ser humano (ARENDT, 2007, p. 74).

O sentido aqui da afirmação de Arendt pode ser visto como de teor bastante "materialista": a vida pública somente era possível depois de atendidas as necessidades 
muito mais urgentes da própria existência. Nesse contexto, a posse de propriedades significava dominar as próprias necessidades vitais e, portanto, ser potencialmente uma pessoa livre; livre para transcender a sua própria existência e ingressar no mundo comum a todos. Ou seja, não podia existir uma esfera pública livre sem o devido estabelecimento e a devida proteção da privatividade. No entanto, Arendt vai além dessa caracterização, destacando um segundo aspecto da esfera privada:

\begin{abstract}
A segunda importante feição não privativa da privatividade é que as quatro paredes da propriedade particular de uma pessoa oferecem o único refúgio seguro contra o mundo público comum não só contra tudo o que nele ocorre mas também contra a sua própria publicidade, contra o fato de ser visto e ouvido. Uma existência vivida inteiramente em público, na presença de outros, torna-se, como diríamos, superficial. Retém a sua visibilidade, mas perde a qualidade resultante de vir à tona a partir de um terreno mais sombrio, terreno este que deve permanecer oculto a fim de não perder sua profundidade num sentido muito real e não subjetivo. O único modo eficaz de garantir a sombra do que deve ser escondido contra a luz da publicidade é a propriedade privada - um lugar só nosso, no qual podemos nos esconder (ARENDT, 2007, p. 81).
\end{abstract}

Em suma, a esfera privada aparece como um importante pressuposto institucional - não restrito ao seu sentido liberal - para a autonomia dos sujeitos políticos e para a própria qualidade da esfera pública.

\title{
Arendt e a ameaça moderna à esfera privada
}

Arendt era da opinião de que o que ela chamava de "características nãoprivativas da privatividade" surgem mais nitidamente quando os homens são ameaçados de perdê-la. Não à toa, é justamente na modernidade que ocorre o que ela chama de ascensão ou promoção do social, em que a preocupação individual com a propriedade privada se torna uma preocupação pública. Com isso, assistimos a uma dissolução das fronteiras entre esfera pública e privada com o consequente desaparecimento de ambas em proveito do social, na medida em que a esfera pública é instrumentalizada em função de fins privados. Ambas as esferas como que se fundem: “a esfera pública porque se tornou função da esfera privada, e a esfera privada porque se tornou a única preocupação comum que sobreviveu” (ARENDT, 2007, p. 79). 
Percebemos portanto que a ameaça à esfera privada, em Arendt, não tem simplesmente o sentido liberal de perda de privacidade ou de propriedade, mas um sentido igualmente público de perda da especificidade e do sentido originário desta outra esfera. A questão que podemos colocar, a partir deste diagnóstico arendtiano, é a de até que ponto o novo fenômeno do big data reforça esta tendência de dissolução das esferas privada e pública, com a consequente perda de liberdade e autonomia (pública) dos indivíduos.

\section{Big data e sociedade: economia, política e subjetividade}

Alguns autores, como Shoshana Zuboff, têm destacado que o fenômeno do Big Data é um signo de uma nova fase do capitalismo, um capitalismo informacional e de vigilância. Empresas como Google e Facebook representariam o protótipo de um novo tipo de empresa capitalista, pautada pela extração massiva e invasiva, e posterior comercialização de dados. Nesse contexto, não se trata apenas simplesmente de extrair dados a despeito dos direitos de privacidade, mas também de influenciar e condicionar o comportamento dos usuários a partir destes dados - seja um comportamento de consumo, seja um comportamento político, como no caso da Cambridge Analytica.

Ou seja, o aspecto central aqui não é tanto o da invasão da privacidade, mas o da extensão do poder de manipulação de comportamentos conferidos pelo big data, que não pode ser compreendido simplesmente num sentido tecnológico mas social. O big data aparece como o componente fundamental de uma nova lógica de acumulação profundamente intencional e altamente influente que ela chama de capitalismo de vigilância. Essa nova forma de capitalismo da informação visa prever e modificar o comportamento humano como meio de produzir receita e controle do mercado (cf. ZUBOFF, 2015, p. 75). Isso porque Zuboff destaca um fato decisivo: três dos sete bilhões de pessoas do mundo agora são mediadas por computador em uma ampla gama de suas atividades diárias, muito além das fronteiras tradicionais do local de trabalho. O mundo renasce como uma série de dados e o texto eletrônico se 
torna universal em escala e escopo. Como as transações são mediadas por computador, podemos observar um comportamento que antes não era observável.

Mas como o big data gera novas oportunidades de negócio? Fiquemos com o exemplo do Google. À medida que aumentavam as pressões pelo lucro, os líderes do Google estavam preocupados com o efeito que as taxas por serviço poderiam ter no crescimento dos usuários. Eles optaram por um modelo de publicidade. A nova abordagem dependia da aquisição de dados do usuário como matéria-prima para análises proprietárias e produção de algoritmos que poderiam vender e direcionar a publicidade por meio de um modelo de leilão exclusivo com cada vez mais precisão e sucesso. Com o rápido crescimento das receitas do Google, elas motivaram uma coleta de dados cada vez mais abrangente. A nova ciência da análise de big data explodiu, impulsionada em grande parte pelo sucesso espetacular do Google.

E como a previsão e a análise são tão cruciais para o Google, todos os dados, por mais triviais que sejam, têm valor potencial. O big data é constituído pela captura de pequenos dados das ações e enunciados mediados por computador dos indivíduos em sua busca por uma vida efetiva. Nada é muito trivial ou efêmero para essa colheita: curtidas no Facebook, pesquisas no Google, e-mails, textos, fotos, músicas e vídeos, localização, padrões de comunicação, redes, compras, movimentos, cada clique, palavra com erros ortográficos, visualização de páginas, e mais. Tais dados são adquiridos, arquivados, resumidos, agregados, analisados, empacotados, vendidos, analisados e vendidos novamente.

O que importa é quantidade, não qualidade. Outra maneira de dizer isso é que o Google é formalmente indiferente ao que seus usuários dizem ou fazem, desde que o façam e façam de maneira que o Google possa capturar e converter em dados. Essa indiferença formal é uma característica proeminente, talvez decisiva, da lógica emergente da acumulação examinada aqui. Para o Google e outros agregadores de big data, os dados são apenas bits. As subjetividades são convertidas em objetos que redirecionam o subjetivo para a mercantilização. Os significados dos usuários individuais não são de interesse para o Google ou outras empresas dessa cadeia.

Segundo a interpretação de Zuboff (2015), temos com o big data um regime institucional em rede onipresente que registra, modifica e consolida a experiência cotidiana, tudo com o objetivo de estabelecer novos caminhos para monetização e 
lucro. "Grande Outro" é o poder soberano de um futuro próximo que aniquila a liberdade alcançada pelo estado de direito. Dentro desse contexto, Zuboff prevê que o próximo passo é um aprofundamento na capacidade de extração de dados, monitoramento e sobretudo manipulação do comportamento em tempo real. Sensores, telefones celulares e outros dispositivos de captura de dados fornecem os "olhos e ouvidos" de um organismo de abrangência mundial.

Mesmo que não queiramos compartilhar todos os elementos deste diagnóstico, é inegável que, com o big data, vemos novas possibilidades de monitorar e manipular a vida cotidiana, a esfera privada. De acordo com Zuboff, as pessoas concordam com a invasão de privacidade representada pelo "Grande Outro" se receberem algo que desejem em troca: uma hipoteca, conselhos médicos, aconselhamento jurídico - ou conselhos do seu assistente digital pessoal.

Zuboff (2015) insiste contudo que essa tendência não é simplesmente tecnológica, pois se as tecnologias são constituídas por traços específicos, o desenvolvimento e a expressão desses traços são moldados pelas lógicas institucionais nas quais as tecnologias são projetadas, implementadas e usadas. O desenvolvimento da Internet e os métodos para acessar a World Wide Web espalharam a mediação de computadores a partir de locais de trabalho limitados e ações especializadas para a onipresença global, tanto na interface institucional quanto nas esferas íntimas da experiência cotidiana. Empresas de alta tecnologia, lideradas pelo Google, perceberam novas oportunidades de lucro nesses fatos. O Google entendeu que se capturasse mais desses dados, os armazenasse e os analisasse, eles poderiam afetar substancialmente o valor da publicidade. Como as capacidades do Google nessa arena se desenvolveram e atraíram níveis históricos de lucro, ela produziu práticas cada vez mais ambiciosas que expandem a lente de dados do comportamento virtual passado para o comportamento real atual e futuro. Novas oportunidades de monetização são, portanto, associadas a uma nova arquitetura global de captura e análise de dados que produz recompensas e punições destinadas a modificar e mercantilizar o comportamento para obter lucro.

Por outro lado, certas análises, como a de Titus Stahl (2016), ressaltam que não apenas no âmbito econômico, mas também no âmbito propriamente político temos neste processo de vigilância massiva ameaças à liberdade e autonomia (privada e 
coletiva) dos cidadãos, o que se constitui, mais amplamente, num perigo à própria ordem democrática. Neste caso, os atores desta extração de dados e vigilância massiva são os próprios Estados, e não mais simplesmente as empresas capitalistas. O episódio mais emblemático a esse respeito foi certamente o das revelações de Edward Snowden sobre as práticas de vigilância global de agências e programas ligados a governos como o americano e o britânico. Esse sistema de vigilância constituiria assim um obstáculo à manutenção da integridade das esferas públicas e às possibilidades efetivas de autoorganização e autodeterminação por parte dos cidadãos e concernidos em diferentes âmbitos da sociedade civil.

Neste caso, seguindo Stahl aqui, podemos afirmar que o big data, em seu potencial de vigilância ubíqua, não ameaça simplesmente a privacidade dos cidadãos, mas sobretudo a própria estruturação da esfera pública. Stahl pretende assim ir além das críticas liberais à vigilância informacional. O seu argumento se desenvolve mostrando fundamentalmente que as novas tecnologias de vigilância indiscriminada em massa propiciaram novas formas de poder aos governos. Essas tecnologias permitem moldar o ambiente comunicativo das comunicações cidadão-cidadão, de modo que certos tipos de relacionamentos se tornam impossíveis e outros se tornam indisponíveis. Ele nos dá o seguinte o exemplo: A prática da "conscientização" é um elemento central do ativismo feminista. É fundamental para essa prática que as mulheres conversem entre si, sem que os homens se envolvam. A razão para isso não é que as mulheres envolvidas nessa prática queiram manter as informações em segredo, mas porque a ausência de homens permite que elas se engajem em certos relacionamentos umas com as outras que, novamente, sustentam uma forma distinta de deliberação política. Só podemos entender essas práticas quando reconhecemos que a capacidade coletiva de um grupo em controlar quem participa de um determinado contexto social equivale a controlar a forma dos relacionamentos que se tornam possíveis nesse contexto e que tal controle sustenta práticas e formas de raciocínio essenciais para a ação política na esfera pública. Assim, é essencial para as relações sociais que sustentam os processos concretos de deliberação dentro deste grupo que ninguém mais esteja envolvido em algumas discussões - nem mesmo o governo em uma capacidade de escuta. 
Ora, se as comunicações nas esferas públicas - notadamente as esferas públicas informais, cujas fronteiras com as esferas privadas são muitas vezes fluidas - estão sujeitas à vigilância, a maioria dos membros do público perde a capacidade de controlar suas relações sociais com outros membros, levando a uma mudança do caráter das relações constitutivas da esfera pública. Como consequência, se um governo se engaja em vigilância indiscriminada, então ele exerce poder político ao moldar o espaço de agência que os papéis sociais disponibilizam aos cidadãos e, assim, as razões que podem potencialmente levá-los à ação (STAHL, 2016, p. 36). Portanto, para Stahl, o que a vigilância em massa restringe não é a liberdade individual, mas a autodeterminação coletiva.

Atualmente, com a crise gerada pela pandemia do coronavírus, essa questão dos riscos trazidos pelo big data e pela vigilância digital às democracias e às liberdades dos cidadãos ganhou enorme relevância. Para diminuir a taxa de contágio e apontar uma saída do isolamento social, diversos países afetados precisaram adotar tecnologias de monitoramento muito mais presentes e o risco disso ser feito por governos com tendências autoritárias é muito grande. Por outro lado, há o perigo da suposta eficiência do modelo oriental de monitoramento se tornar uma tendência mundial de governança. Pensando em termos distópicos, mas também se baseando na realidade de alguns países asiáticos durante o combate ao vírus, Byung Chul-Han fala a esse respeito de um "Estado policial digital", promotor de uma "biopolítica digital":

Ao que parece o big data é mais eficaz para combater o vírus do que os absurdos fechamentos de fronteiras que estão sendo feitos nesses momentos na Europa. Graças à proteção de dados, entretanto, não é possível na Europa um combate digital do vírus comparável ao asiático. Os fornecedores chineses de telefonia celular e de Internet compartilham os dados sensíveis de seus clientes com os serviços de segurança e com os ministérios de saúde. O Estado sabe, portanto, onde estou, com quem me encontro, o que faço, o que procuro, em que penso, o que como, o que compro, aonde me dirijo. É possível que no futuro o Estado controle também a temperatura corporal, o peso, o nível de açúcar no sangue etc. Uma biopolítica digital que acompanha a psicopolítica digital que controla ativamente as pessoas. (HAN, 2020a)

A principal preocupação de Chul-Han é que a provável superioridade desse modelo asiático no combate ao coronavírus permita com que a China possa vender seu "Estado policial digital" como um modelo de sucesso contra a pandemia. 
Seguindo aqui Naomi Klein, ele nota que o choque e a comoção gerada por uma crise dessa natureza é um momento propício para o estabelecimento de um novo sistema de regras. É claro que as medidas atuais de isolamento e monitoramento são necessárias para controlar a pandemia, mas até que ponto não existe o risco de a exceção temporária se tornar a regra no mundo pós-pandemia?

E então ele coloca uma questão crucial: “O vírus está deixando o liberalismo e individualismo ocidental obsoleto? Ou a epidemia incontrolável com incontáveis mortes é o preço da liberdade que temos que aceitar?” (HAN, 2020b). Só é importante acrescentar - eis a tônica geral do meu argumento neste artigo - que as liberdades individuais e o direito à privacidade possuem um valor coletivo e público, cruciais para garantir a integridade da vida democrática e da esfera pública. Portanto, não se trata de opor um direito individual (a privacidade) ao interesse coletivo no combate ao vírus, mas sim de avaliar criticamente em que medida políticas de caráter excepcional se tornarão ou não um "novo normal". A oposição aqui se dá entre dois modelos públicos de organização social, em que, de um lado, temos um primado "hobbesiano" da segurança, e, de outro, a liberdade individual e coletiva como norte da política.

Mas e quando são os próprios indivíduos que têm interesse em coletar seus dados através das novas tecnologias digitais de informação? Mas e quando eles não precisam ser vigiados para que se lhes extraiam dados? O movimento Quantified Self é apenas o exemplo mais emblemático deste fenômeno da metrificação/dataficação do velho Adágio "Conhece-te a ti mesmo". Com efeito, as práticas de automonitoramento/rastreamento (self-tracking) via tecnologias/aparelhos digitais têm se tornado cada vez mais comuns.

Muitas pessoas que não padecem de doenças sérias começaram a utilizar sensores "vestíveis" e computadores para monitorar sua saúde e suas atividades. Os dispositivos — incorporados em suportes que vão de smartphones a relógios de pulso, de braçadeiras a roupas íntimas — registram diversos dados biométricos, como a pressão sanguínea, por exemplo. Os dados alimentam sofisticados programas de computador, que aconselham o usuário a mudar sua dieta e sua rotina para usufruir de melhor saúde e de uma vida mais longeva e produtiva. 
Claro, monitorar, medir e registrar elementos do corpo e da vida como uma forma de autoaperfeiçoamento ou autorreflexão são práticas que foram discutidas desde os tempos antigos. No entanto, não haveria nenhuma especificidade dos métodos digitais contemporâneos?

Senão vejamos. Em muitos casos, o autorrastreamento é um empreendimento pessoal puramente voluntário iniciado pela pessoa que está se engajando nele. No entanto, como mostra Deborah Lupton (2016), existem várias maneiras pelas quais o autorrastreamento está sendo encorajado, ou mesmo imposto às pessoas, predominantemente para que os objetivos dos outros sejam atingidos. As pessoas agora são frequentemente encorajadas, "empurradas", obrigadas ou coagidas a monitorar os aspectos de suas vidas, de modo a produzir dados pessoais que também podem ser usados para os propósitos de outros, notadamente na esfera do trabalho.

\section{Pressupostos epistêmicos e consequências ideológicas do Big Data: por uma reatualização do conceito habermasiano de ideologia tecnocrática}

De uma perspectiva filosófica, surgem várias questões interessantes sobre a busca pelo monitoramento e medição de elementos do corpo, comportamento e hábitos. Quais são as suposições tácitas que sustentam os modos contemporâneos de automonitoramento? Por que as pessoas são atraídas pelo autorrastreamento? Como eles interpretam e usam os dados que produzem? Como os conceitos do corpo, do eu, das relações sociais e dos comportamentos sociais são configurados e negociados por meio desses dados? Quais são as relações de poder e as desigualdades de poder inerentes às culturas de autorrastreamento?

Muitas questões às quais não posso dar resposta agora. Mas gostaria de sublinhar um ponto que me parece particularmente relevante, que diz respeito por assim dizer à epistemologia que se constitui como pressuposto desse interesse pelos dados. 
A "ideologia do big data" permitiria substituir as próprias capacidades de reflexão, deliberação e decisão dos indivíduos (modernos), que em sua autonomia ainda são por demais instáveis e limitados. O indivíduo não é mais quem tem razão, aquele que deve decidir, e sua experiência não é mais sacralizada. Agora os números falam e decidem por ele. Teríamos então uma espécie de "ideologia tecnocrática 2.0”, para fazer menção a um conceito de Habermas (1983). Retomarei este ponto logo adiante.

Ora, como nos mostra Antoinette Rouvroy (2016), os dados nunca são meramente "dados". Eles são, na melhor das hipóteses, apenas transcrições "passivas" de "fatos". Eles próprios dependem de normatividades sociais, relações de poder e dominação em vigor. Decidir com base nos dados, como fazem os algoritmos, significa pretender decidir de modo objetivo, com base em fatos cuja contingência é esquecida, o que não é o mesmo que governar de acordo com a justiça, a qual pede que devemos levar em conta as condições dos fatos, e - quando essas condições são injustas - que elas sejam mudadas. Se, por exemplo, na prática, empregos mais bem pagos são ocupados por homens, algoritmos de recomendação alimentado com esses dados, usados com fins de tornar as decisões de contratação ou promoção mais objetivas, reverberarão "passivamente" apenas o resultado de preconceitos contra as mulheres e produzirão perfis de desempenho favoráveis aos homens em detrimento das candidatas do sexo feminino. A chamada otimização das decisões pelo recurso à chamada inteligência dos dados é o oposto de uma "mudança de mundo". A ignorância das causas dos fenômenos em favor da indução puramente estatística baseada na detecção de correlações é um tecnoconservadorismo que torna os preconceitos de nossa "realidade social” invisíveis e indiscutíveis.

Um outro exemplo que ilustra como o modo opaco pelo qual os próprios algoritmos funcionam dificulta a crítica a essa regulação social algorítmica é fornecido em uma entrevista por Cathy O’Neil, matemática e especialista na área, durante entrevista ao jornal El Pais:

O distrito escolar de Washington começou a usar o sistema de pontuação Mathematica para identificar os professores menos produtivos. Foram demitidos 205 docentes depois que esse modelo os considerou maus professores. Atualmente não temos como saber apenas com dados se um trabalhador é eficiente. O dilema se você é ou não um bom professor não pode ser resolvido com tecnologia, é um problema humano. Muitos desses 
professores não puderam reclamar, porque o secretismo sobre como o algoritmo funciona lhes priva desse direito. Ao esconder os detalhes do funcionamento, fica mais difícil questionar a pontuação ou protestar (MENÁRGUEZ, 2018).

Ou seja, é preciso uma crítica epistêmica da suposta eficiência e neutralidade técnica do big data, caso contrário estaremos não apenas contribuindo para a invisibilização de eventuais interesses e injustiças sociais, mas, mais geralmente, solapando as bases da autonomia privada das pessoas bem como da autonomia pública dos cidadãos.

É nessa perspectiva que, para finalizar este artigo, eu gostaria de sugerir uma reapropriação e uma reatualização do conceito habermasiano de ideologia tecnocrática, a fim de dar conta criticamente do que chamei acima de ideologia do big data. Este conceito é desenvolvido por Habermas para explicar como a técnica e ciência podem ter assumido um papel ideológico no capitalismo tardio. Nesse contexto, a evolução do sistema social parece estar determinada pela lógica do progresso técnico-científico. A legalidade imanente de tal progresso parece produzir coações materiais pelas quais se deve pautar uma política que se submete às necessidades funcionais. E quando essa aparência se impôs com eficácia, então a mera referência propagandística à ciência e à técnica é capaz de explicar e legitimar por que é que, nas sociedades modernas avançadas, uma formação democrática da vontade política perde relevância em relação às questões práticas e "deve" ser substituída por decisões plebiscitárias acerca de equipes alternativas de administradores, responsáveis por dar continuidade ao "trabalho técnico", supostamente imune a preferências e interesses particulares. Assim, as questões práticas, intrínsecas ao jogo político democrático, se confundem com meras questões técnicas.

Mas Habermas está mesmo interessado no modo como tal ideologia foi capaz de penetrar na consciência de fundo das massas despolitizadas. Ou seja, o foco é o campo da subjetividade conformada socialmente pelo capitalismo tardio. E, segundo ele, a eficácia peculiar desta ideologia reside em dissociar a autocompreensão culturalmente e simbolicamente mediadas da sociedade e dos indivíduos, sendo que esta é substituída por um modelo cientificista e, no limite, pela autocoisificação dos seres humanos. No fundo, é o próprio apagamento da diferença entre experiência simbólica linguisticamente mediada e pautada por normas, de um lado, e 
comportamento adaptativo seguindo um modelo behaviorista do estímulo externo, de outro, que marca a consciência tecnocrática investigada por Habermas. Em face dos novos desenvolvimentos, poderíamos dizer que essa consciência tecnocrática se desenvolveu a ponto de reduzir tanto a sociedade quanto nossas próprias individualidades a um conjunto de dados auferidos pelas tecnologias digitais. Se é assim, são os algoritmos que devem determinar de fora o meu comportamento e até mesmo diversos tipos de decisões práticas, desde a avaliação de um professor até, no limite, questões políticas. Afinal, com o big data, os algoritmos me conhecem melhor do que eu mesmo.

Nesse sentido, questões de ordem prática (ética e política) e existencial tendem a se confundirem (e nisso reside o aspecto ideológico do big data) com questões de ordem técnica, que por isso devem ser decididas - de modo supostamente mais eficaz e neutro - por um algoritmo alimentado por uma base de dados. A decisão será tanto mais eficaz quanto maior for a base de dados. Ora, como vimos no exemplo da passagem acima citada, "o dilema se você é ou não um bom professor não pode ser resolvido com tecnologia, é um problema humano".

De fato, segundo Habermas, tal configuração ideológica é específica e, em certo sentido, mais eficiente e perigosa do que as versões clássicas de ideologia:

A consciência tecnocrática é, por um lado, "menos ideológica" que todas as ideologias anteriores; pois ela não possui a violência opaca de um ofuscamento que joga apenas com a ilusão de satisfação dos interesses. Por outro lado, a vítrea ideologia de fundo hoje dominante, que transforma a ciência em fetiche, é mais irresistível e mais abrangente do que as ideologias do tipo antigo, pois com o velamento das questões práticas, ela não somente justifica um interesse de dominação de uma classe determinada e oprime a necessidade parcial de emancipação por parte de outra classe, como também atinge o interesse emancipatório da espécie humana, como tal (HABERMAS, 1983, p. 335).

Nos termos trabalhados ao longo do artigo, poderíamos insistir portanto que, além da invisibilização de injustiças sociais, a ideologia do big data - podendo aqui ser interpretada como o aprofundamento da ideologia tecnocrática diagnosticada por Habermas no final da década de 60 - representa notadamente uma ameaça à nossa autocompreensão moderna enquanto indivíduos, dotados de uma experiência simbólica própria, capazes de agir e tomar decisões de modo autônomo tanto no âmbito privado quanto - intersubjetivamente - no âmbito público, sem depender de 
um critério externo outrora buscado na natureza ou em Deus. É tal pressuposto antropológico "humanista", a grande marca da modernidade, que pode estar sendo posto em xeque pelo avanço dos processos vinculados ao fenômeno do big data e dos algoritmos.

Não se trata, evidentemente, de fazer profissão de fé tecnofóbica, mas apenas de explicitar e analisar criticamente alguns dos pressupostos epistêmicos, bem como das consequências ideológicas, que aparecem nas entrelinhas de um fenômeno que está longe de ser exclusivamente "tecnológico". Aliás, para falar aqui como Heidegger (2007), a essência da técnica não é técnica.

$\mathrm{Na}$ época que Habermas cunhou esse conceito, o seu foco se dirigia sobretudo à esfera pública, isto é, ao modo como as decisões democráticas eram substituídas pela tecnocracia. Hoje, essa problemática se torna ainda mais dramática, na medida em que temos, de um lado, uma capacidade de vigilância, manipulação e condicionamento efetivamente potencializada pelo big data, e, de outro, um aprofundamento daquilo que Habermas chamava de autocompreensão objetificada de si e da sociedade, que é o que, no fundo, legitima e abre o caminho para tal vigilância e manipulação. O risco reside na possibilidade de, de fato, abrirmos mão de nossas capacidades decisórias, não mais tanto em proveito de uma equipe de técnicos - como na década de 60 - mas agora em favor de sistemas e máquinas "artificialmente inteligentes". E se a esfera pública continua ameaçada, o foco agora reside na esfera privada; isto é, na "mudança estrutural" que esta tem sofrido durante o amplo processo de digitalização que estamos vivenciando. Pois é a partir da nossa esfera privada - cujo acesso concedemos, voluntária ou involuntariamente, aos diversos dispositivos e aplicativos — que essa lógica decisória, que dispensa o contexto prático e simbólico de nossas próprias experiências, se espraia potencialmente para todo o tecido social.

\section{Considerações finais: o futuro do indivíduo moderno em questão}

O big data significa o acesso a dados inéditos das pessoas, ainda que não necessariamente individuais. Por outro lado, os algoritmos não são neutros, tampouco 
os dados que lhes servem de base. Isso produz uma capacidade igualmente inédita de manipulação de comportamentos e percepções de mundo via esfera privada - vide o caso recente envolvendo o Facebook e a Cambridge Analytica durante as eleições americanas de 2016. Ora, tendo em vista que vimos que a esfera privada é essencial para o bom funcionamento da própria esfera pública, temos com a regulação algorítmica e com o big data uma ameaça importante, potencialmente crucial, para a autonomia pública dos cidadãos.

Tendo em vista o caráter ubíquo e massivo da digitalização da vida, é forçoso admitir que se trata de um fenômeno cujo escopo é difícil de medir, mas sobre o qual é necessário pensar, dada a novidade do fenômeno. $\mathrm{Na}$ falta de respostas mais concretas, já que esse artigo teve como objetivo primordial muito mais chamar a atenção para um campo problemático que surge com este novo fenômeno e lançar mão de uma interpretação tão somente preliminar, gostaria de concluir ao menos com a tentativa de formular algumas questões que me parecem relevantes nesse cenário. Esse fenômeno seria capaz de alterar essa percepção básica da modernidade, de que somos seres autônomos, responsáveis e os únicos capazes legitimamente de tomar determinadas deliberações e decisões? Essa capacidade de manipulação de dados de nossa vida cotidiana (esfera privada) seria capaz de minar inclusive a autonomia pública, ameaçando a democracia, isto é, a integridade das esferas públicas e das possibilidades reais de autodeterminação? Se a democracia efetiva sempre foi um projeto, ainda não realizado plenamente, ela se torna uma utopia mais distante com o big data? Diante de tudo isso, a antropologia política da modernidade pode ser mantida? Estaríamos vivendo o fim não apenas do antropocentrismo e humanismo modernos, mas da própria noção de indivíduo autônomo, cuja experiência, sentimentos e racionalidade foram sacralizados e adquiriram centralidade absoluta nas concepções políticas modernas? É possível uma autonomia pública em um cenário em que nossa vida cotidiana e privada é cada vez mais esquadrinhada por mecanismos de extração de dados?

Em suma, o fim do humanismo e do antropocentrismo, tão desejado por alguns, deve nos conduzir ao fim do indivíduo moderno e das concepções tradicionais de autonomia privada e público? Como compreenderíamos a política então? Trata-se evidentemente de questões em aberto, mas cuja reflexão é hoje urgente. 


\section{Referências}

ARENDT, H. A Condição Humana. 10a edição. Rio de Janeiro: Forense Universitária, 2007.

COHEN, J. Examined Lives: Informational Privacy and the Subject as Object. Stanford Law Review, v. 52, n. 5, p. 1373-1438, 2000.

FLORIDI, L. The Fourth Revolution: How the infosphere is reshaping human reality. New York ; Oxford: Oxford University Press, 2014.

HABERMAS, J. Faktiziität und Geltung. Frankfurt: Suhrkamp, 1994.

HABERMAS, J. Técnica e Ciência como Ideologia. São Paulo: Abril Cultural, 1983. (Coleção Os Pensadores- Escola de Frankfurt).

HAN, B.-C. O coronavírus de hoje e o mundo de amanhã. El País, 22 mar. 2020a. Disponível em: https://brasil.elpais.com/ideas/2020-03-22/o-coronavirus-de-hoje-e-o-mundo-deamanha-segundo-o-filosofo-byung-chul-han.html. Acesso em: 30 abr. 2020.

HAN, B.-C. Pandemia do coronavírus indica retorno à sociedade disciplinar. Folha de São Paulo, 5 abr. 2020b. Disponível em: https://www1.folha.uol.com.br/mundo/2020/04/pandemia-docoronavirus-indica-retorno-a-sociedade-disciplinar.shtml. Acesso em :30 abr. 2020.

HEIDEGGER, M. A questão da técnica. Sci. stud., São Paulo , v. 5, n. 3, p. 375-398, Sept. 2007. Disponível em: http://www.scielo.br/scielo.php?script=sci_arttext\&pid=S167831662007000300006\&lng=en\&nrm=iso. Acesso em: 28 abr. 2020. https://doi.org/10.1590/S1678-31662007000300006.

LUPTON, D. The diverse domains of quantified selves: self-tracking modes and dataveillance. Economy and Society, v. 45, n. 1, p. 101-122, jan. 2016.

MENÁRgUEZ, A. Os privilegiados são analisados por pessoas; as massas, por máquinas. El País, 21 nov. 2018. Disponível em: https://brasil.elpais.com/brasil/2018/11/12/tecnologia/1542018368_035000.html.

Acesso em: 23 dez. 2018.

REPA, L. A cooriginariedade entre direitos humanos e soberania popular: a crítica de Habermas a Kant e Rousseau. Trans/Form/Ação, vol. 36, pp. 103-120, 2013.

ROUSSEAU, J-J. Do contrato social. Ed. Os Pensadores. São Paulo: Nova Cultural, 1987.

ROUVROY, A. Le gouvernement algorithmique ou l'art de ne pas changer le monde. La revue nouvelle, n. 8, 2016. Disponível em: https://www.academia.edu/28370856/Le_gouvernement_algorithmique_ou_lart_de_ne_pas_cha nger_le_monde. Acesso em: 23 dez. 2018.

STAHL, T. Indiscriminate Mass Surveillance and the Public Sphere. Ethics and Information Technology, v. 18, n. 1, p. 33-39, 2016. 
ZUBOFF, S. Big Other: Surveillance Capitalism and the Prospects of an Information Civilization. Social Science Research Network, 4 abr. 2015. Disponível em: https://papers.ssrn.com/abstract=2594754. Acesso em: 14 ago. 2018.

RECEBIDO: 06/05/2020

RECEIVED: 05/06/2020

APROVADO: 01/10/2020

APPROVED: $10 / 01 / 2020$ 